\title{
Influence of proxy respondents in children's health interview surveys
}

\author{
L Rajmil, E Fernández, R Gispert, M Rué, J P Glutting, A Plasència, A Segura
}

\begin{abstract}
Study objectives-To study the influence of the proxy respondent on health interview surveys in children.

Design-Cross sectional study.

Setting-Children under the age of 15 years drawn from the general population of Catalonia, Spain.

Participants-The Catalan Health Interview Survey consisted of a multistage probability sample representative to the population of Catalonia. The sample size was 2433 children younger than 15 years of age. The interviews were answered by proxy respondents (the mother, father, or other carer), with the questionnaire adapted for the proxy respondent. Logistic regression models were used to analyse the relation between the proxy respondent's characteristics and health status and health care utilisation, controlling for the effect of sociodemographic factors.

Main results-Proxy respondent's characteristics influenced the reports of chronic conditions and accidents within the last year. Proxy respondents over 55 years $(\mathrm{OR}=0.47 ; 95 \% \mathrm{CI}=0.26,0.82)$, men $(\mathrm{OR}=$ $0.69 ; 95 \% \mathrm{CI}=0.53,0.89)$, the father $(\mathrm{OR}=$ $0.66 ; 95 \% \mathrm{CI}=0.50,0.89)$, and the grandparents $(O R=0.49 ; 95 \% C I=0.26,0.89)$, reported a lower rate of chronic conditions. Age of the proxy 55 years or greater $(\mathrm{OR}=$ $0.41 ; 95 \% \mathrm{CI}=0.20,0.82)$, men $(\mathrm{OR}=0.70$; $95 \% \mathrm{CI}=0.52,0.94)$, fathers $(\mathrm{OR}=0.68 ; 95 \%$ $\mathrm{CI}=0.49,0.92)$, and grandparents $(\mathrm{OR}=$ $0.40 ; 95 \% \mathrm{CI}=0.18,0.85)$ showed a lower probability to report accidents. No variables related to the proxy were associated with physician visits or hospitalisation in the previous year.

Conclusions-Selected characteristics of the proxy respondent can influence responses to health surveys involving children. A minimum set of basic data should be collected from the proxy respondent to evaluate different patterns of response. (F Epidemiol Community Health 1999;53:38-42)
\end{abstract}

Proxy respondents are used in health surveys and epidemiological studies to substitute for unavailable persons selected for interviews, to make sampling more efficient, and to obtain information from the largest number of people. The reasons for the use of proxy respondents can be the absence of the chosen person at the time of the interview, inability of the chosen person to answer or in the case of children their age.

The studies of proxy respondents have described two basic types of errors associated with their use: the "proxy effect", ${ }^{12}$ which consists of the under-reporting of events because of lack of knowledge, and the "saliency principle", ${ }^{3}$ which describes the effect of proxy respondents reporting more accurately those events that they interpret as more relevant.

The main factors analysed that may influence the answers of the proxy respondents have been: the question asked, the characteristics of the proxy respondent, and the proxy respondent's relationship with the selected person.

Bias reduces as the information collected becomes more specific, whereas it increases for responses to questions evaluating psychological conditions, ${ }^{4}$ pain, ${ }^{5}$ or quality of life in chronic conditions ${ }^{6}$ with an underestimation of functional capacity. In case-control studies, when exposure to risk factors was analysed, an overestimation of exposure to tobacco in occasional smokers were found. ${ }^{7}$ This type of bias has been noted in a study of cardiovascular risk in young women using oral contraceptives. ${ }^{8}$ Also, a $4 \%$ under-reporting of physician visits in the last year and a $2 \%$ under-reporting of hospitalisation was found in responses from proxy respondents in the 1978 National Health Interview Survey (NHIS), ${ }^{9}$ with an underestimation of 0.65 visits/person/year.

The proxy respondent's answers seem to be more reliable in studies of children than in adults. ${ }^{10}$ Andersen et $a l^{11}$ found higher agreement between the responses of proxy respondents and their children than in the self reports of adults and their proxies. Nevertheless, there is a lower level of agreement in the responses of proxies when dealing with more subjective dimensions of health, ${ }^{12}$ such as the quality of life of children with chronic diseases and cerebral tumours. ${ }^{13}$

Information about the child is generally collected from the mother in health surveys and epidemiological studies. Commonly, the father, grandparents or the carer responsible for the child is interviewed in the cases when it is not possible to interview the mother. ${ }^{14}$

The aim of this work was to study the ability of proxy respondents to answer questions relating to the health of a population of children under 15 years of age. More specifically, to analyse whether some characteristics of the proxy respondent (age, sex, family relationship with the child, and number of hours dedicated to caring for the child) affect the responses to the survey.

\section{Methods}

Data were obtained from the Catalan Health Interview Survey (CHIS), which was undertaken during 1994. The CHIS consisted of a 
Table 1 Characteristics of children according to age and sex of proxy respondent, relationship to child proxy, and hours daily dedicated to caring for the child

\begin{tabular}{|c|c|c|c|c|c|c|c|c|c|c|c|c|c|c|c|}
\hline \multirow[b]{4}{*}{ Children } & \multirow[b]{4}{*}{ Number } & \multicolumn{14}{|c|}{ Characteristics of proxy respondents } \\
\hline & & \multicolumn{3}{|l|}{ Age } & \multicolumn{3}{|l|}{ Sex } & \multicolumn{5}{|c|}{ Relationship } & \multicolumn{3}{|c|}{ Hours daily } \\
\hline & & $<55$ & $\geqslant 55$ & $p$ & Female & Male & $p$ & Father & Mother & Grandparents & Other & $p$ & $0-12$ & $13-24$ & $p$ \\
\hline & & 2316 & 117 & & 1932 & 499 & & 463 & 1789 & 97 & 82 & & 2030 & 382 & \\
\hline \multicolumn{16}{|l|}{ Age } \\
\hline$<1$ & 238 & 96.5 & 3.5 & & 79.9 & 20.1 & & 20.1 & 74.8 & 4.9 & 0.2 & & 54.8 & 45.2 & \\
\hline $1-4$ & 398 & 97.9 & 2.1 & & 79.2 & 20.8 & & 20.5 & 74.3 & 3.0 & 2.2 & & 82.8 & 17.2 & \\
\hline $5-10$ & 959 & 94.7 & 5.3 & & 79.3 & 20.7 & & 18.9 & 72.9 & 4.6 & 3.6 & & 86.3 & 13.7 & \\
\hline $11-14$ & 837 & 94.1 & 5.9 & 0.021 & 79.7 & 20.3 & 0.991 & 18.2 & 73.6 & 3.6 & 4.6 & 0.062 & 90.8 & 9.2 & $<0.001$ \\
\hline \multicolumn{16}{|l|}{ Sex } \\
\hline Male & 1283 & 94.8 & 5.2 & & 79.4 & 20.6 & & 19.2 & 73.1 & 4.8 & 2.8 & & 84.8 & 15.2 & \\
\hline Female & 1150 & 95.6 & 4.4 & 0.349 & 79.5 & 20.5 & 0.94 & 18.8 & 74.1 & 3.1 & 4.0 & 0.068 & 83.4 & 16.6 & 0.346 \\
\hline \multicolumn{16}{|l|}{ Social class } \\
\hline I-II & 530 & 96.2 & 3.8 & & 76.6 & 23.4 & & 22.9 & 71.1 & 3.3 & 2.7 & & 84.6 & 15.4 & \\
\hline III & 464 & 97.0 & 3.0 & & 74.5 & 25.5 & & 23.6 & 69.7 & 3.6 & 3.1 & & 85.9 & 14.1 & \\
\hline IVa-IVb-V & 1357 & 94.5 & 5.5 & 0.054 & 81.8 & 18.2 & 0.001 & 16.4 & 75.6 & 4.1 & 3.9 & 0.005 & 83.8 & 16.2 & 0.573 \\
\hline \multicolumn{16}{|c|}{ Number of family members } \\
\hline$<5$ & 1705 & 97.3 & 2.7 & & 79.5 & 20.5 & & 19.9 & 76.2 & 2.3 & 1.6 & & 84.0 & 16.0 & \\
\hline$\geqslant 5$ & 728 & 90.3 & 9.7 & $<0.001$ & 79.3 & 20.7 & 0.885 & 17.0 & 67.4 & 8.1 & 7.5 & $<0.001$ & 84.7 & 15.3 & 0.662 \\
\hline
\end{tabular}

Missing cases: social class in 81 cases, sex of proxy in two cases, relationship with proxy in two cases, and hours daily dedicated to caring for the child in 21 cases.

multistage probability sample in each of the eight health regions of Catalonia, Spain. The sample was representative of each health region and adequately weighted to cover the entire non-institutionalised population of Catalonia. ${ }^{15}$ The sample size for all ages was 15000 , with 2433 subjects younger than 15 years. The health data for children under 15 years were obtained from proxy respondents (the mother, father, or other carer), by means of a structured interview adapted for the proxy respondent.

The proxy respondent questionnaire was similar to that used for regular respondents of the CHIS but adapted to indirect questions. It excluded those questions referring to mental health, satisfaction with health services, and opinion about the health system. Those questions were excluded because of the limitations identified in previous studies that found less reliable and valid responses referring to this kind of subjective questions. ${ }^{4-6}$

To be eligible as a proxy respondent the subject had to meet two conditions: firstly, it was imperative to be responsible for caring for the child, and secondly, it was desirable to live with him or her to guarantee an in depth knowledge of the child. ${ }^{16}$

Sociodemographic variables of the child and their family that were taken into account in the analysis were age, sex, number of family members, and social class. Social class was based on the occupation of the head of the household, ${ }^{17}$ and grouped into three categories: I+II (upper), III (middle), and IVa+IVb+V (lower). The descriptive variables of the health of the child were health status, perceived as good (grouping the categories excellent/very good/ good) or poor (grouping the categories fair/ poor), chronic restriction of activity in the last year (no/yes), reporting of any chronic condition (no/yes) and accidents in the last year (no/ yes). The health care service utilisation variables analysed were physician visits in the last 15 days (no/yes) and hospitalisation in the last year (no/yes). The variables of the proxy respondent were age ( $<55$ years and $\geqslant 55$ years), sex, type of relationship with child (father, mother, grandparents and other family), and the hours dedicated daily to caring for the child (0-12 hours and 13-24 hours).

Table 2 Relation between declaring poor health status, presenting at least one chronic condition, presenting chronic restriction of activities and having had an accident, and selected characteristics of children and proxy respondent

\begin{tabular}{|c|c|c|c|c|c|c|c|c|}
\hline & \multicolumn{2}{|c|}{ Poor health } & \multicolumn{2}{|c|}{ Chronic condition } & \multicolumn{2}{|c|}{ Chronic restriction } & \multicolumn{2}{|c|}{ Accident } \\
\hline & $\%$ & OR $(95 \% C I)$ & $\%$ & OR $(95 \% C I)$ & $\%$ & $O R(95 \% C I)$ & $\%$ & $O R(95 \% C I)$ \\
\hline \multicolumn{9}{|l|}{ Social class } \\
\hline I-II & 2.8 & 1 & 18.8 & 1 & 2.1 & 1 & 16.4 & 1 \\
\hline III & 3.1 & $1.04(0.47,2.28)$ & 24.2 & $1.39(1.01,1.89)$ & 5.5 & $2.35(1.17,4.71)$ & 16.6 & $1.03(0.73,1.47)$ \\
\hline IVa-IVb-V & 5.3 & $2.04(1.12,3.70)$ & 25.7 & $1.49(1.15,1.92)$ & 5.6 & $2.44(1.32,4.49)$ & 17.9 & $1.08(0.85,1.43)$ \\
\hline \multicolumn{9}{|c|}{ Proxy characteristics } \\
\hline \multicolumn{9}{|l|}{ Age } \\
\hline$<55$ & 4.1 & 1 & 24.2 & 1 & 4.9 & 1 & 17.5 & 1 \\
\hline$\geqslant 55$ & 6.5 & $1.83(0.84,3.96)$ & 13.1 & $0.47(0.26,0.82)$ & 3.5 & $0.69(0.25,1.92)$ & 6.4 & $0.41(0.20,0.82)$ \\
\hline \multicolumn{9}{|l|}{ Sex } \\
\hline Female & 4.3 & 1 & 25.2 & 1 & 5.3 & 1 & 18.1 & 1 \\
\hline Male & 3.7 & $1.14(0.66,1.94)$ & 17.9 & $0.69(0.53,0.89)$ & 3.3 & $0.76(0.44,1.28)$ & 12.7 & $0.70(0.51,0.94)$ \\
\hline \multicolumn{9}{|c|}{ Relationship with children ${ }^{\star}$} \\
\hline Mother & 4.2 & 1 & 25.6 & 1 & 5.3 & 1 & 18.7 & 1 \\
\hline Father & 3.8 & $1.24(0.71,2.15)$ & 17.6 & $0.66(0.50,0.86)$ & 3.5 & $0.79(0.46,1.35)$ & 13.0 & $0.68(0.49,0.92)$ \\
\hline Grandparents & 7.4 & $1.60(0.63,4.00)$ & 15.2 & $0.49(0.26,0.89)$ & 4.5 & $0.78(0.26,2.26)$ & 10.7 & $0.40(0.18,0.85)$ \\
\hline Other & 3.4 & $1.27(0.41,3.87)$ & 28.7 & $1.05(0.63,1.74)$ & 9.0 & $0.74(0.23,2.34)$ & 11.8 & $0.54(0.26,1.09)$ \\
\hline \multicolumn{9}{|l|}{ Hours daily } \\
\hline $0-12$ & 3.4 & 1 & 22.7 & 1 & 4.4 & 1 & 16.1 & 1 \\
\hline $13-24$ & 8.4 & $2.53(1.51,4.01)$ & 30.0 & $1.31(0.99,1.72)$ & 7.0 & $1.44(0.88,2.40)$ & 23.6 & $1.47(1.07,2.00)$ \\
\hline
\end{tabular}

Percentages are age standardised by the census population of Catalonia 1991. OR estimates adjusted for age and sex of the child and the other variables in the table. *Adjusted for all the variables except age and sex of the proxy. 
The variables related to the age of the child (such as the reporting of chronic conditions) were age standardised by the direct method, using as standard the 1991 census population data of Catalonia, in four groups (less than 1 year, 1-4, 5-9 and 10-14 years). In the same way, accidents and hospitalisation reported, which were also related to sex, were standardised according to age and sex.

Logistic regression models were fitted to analyse the relation between the proxy respondent's characteristics and their responses on the health status of the child and the child's health care utilisation questions, simultaneously allowing for the effect of sociodemographic factors. ${ }^{18}$ As the variables age and sex of the proxy and the variable indicating the type of relationship between the carer and child were highly correlated, those variables were not included when the variable relation was fitted.

\section{Results}

Table 1 shows the sociodemographic characteristics of the 2433 children included in the sample, by age, sex, relationship with proxy respondent, and hours that were dedicated to caring for the child. Proxies over 55 years old answered for the largest percentage of children over 4 years old, in families with the lowest socioeconomic level, and in families with more than five members. The proxy was most often a woman in families of lower social class. The proxy reported a daily number of hours of caring greater than 12 hours for the majority of children under 1 year old. The mother was the proxy respondent most frequent in all the

Table 3 Relation between declaring at least one visit in the last 15 days, having had at least one stay in hospital in the last year, and selected characteristics of children and proxy respondent

\begin{tabular}{|c|c|c|c|c|}
\hline & \multicolumn{2}{|c|}{ Physician visits } & \multicolumn{2}{|c|}{ Hospitalisation in the last year } \\
\hline & $\%$ & OR $(95 \% C I)$ & $\%$ & $O R(95 \% C I)$ \\
\hline \multicolumn{5}{|l|}{ Social class } \\
\hline I-II & 22.7 & 1 & 5.4 & 1 \\
\hline III & 19.7 & $0.83(0.59,1.16)$ & 5.0 & $0.75(0.41,1.34)$ \\
\hline IVa-IVb-V & 21.6 & $0.89(0.68,1.16)$ & 6.5 & $0.95(0.60,1.49)$ \\
\hline \multicolumn{5}{|c|}{ Health characteristics } \\
\hline \multicolumn{5}{|c|}{ Health status perception } \\
\hline Good & 20.7 & 1 & 5.4 & 1 \\
\hline Poor & 41.5 & $1.51(0.91,2.49)$ & 17.6 & $2.13(1.12,4.03)$ \\
\hline \multicolumn{5}{|l|}{ Chronic condition } \\
\hline No & 18.5 & 1 & 4.5 & 1 \\
\hline Yes & 31.7 & $1.99(1.54,2.56)$ & 11.4 & $1.77(1.16,2.69)$ \\
\hline \multicolumn{5}{|c|}{ Chronic restriction } \\
\hline No & 20.6 & 1 & 4.9 & 1 \\
\hline Yes & 37.7 & $0.99(0.61,1.60)$ & 26.6 & $5.51(3.21,9.45)$ \\
\hline \multicolumn{5}{|c|}{ Restriction 15 previous days } \\
\hline No & 16.2 & 1 & 5.5 & 1 \\
\hline Yes & 64.0 & $8.53(6.33,11.47)$ & 9.5 & $1.40(0.85,2.29)$ \\
\hline \multicolumn{5}{|c|}{ Proxy respondent characteristics } \\
\hline \multicolumn{5}{|l|}{ Age } \\
\hline$<55$ & 22.9 & 1 & 5.8 & 1 \\
\hline$\geqslant 55$ & 16.7 & $0.85(0.47,1.51)$ & 6.2 & $1.18(0.47,2.94)$ \\
\hline \multicolumn{5}{|r|}{$1.10(0.47,2.94)$} \\
\hline Female & 23.9 & 1 & 6.1 & 1 \\
\hline Male & 17.6 & $0.85(0.64,1.12)$ & 5.5 & $1.06(0.67,1.67)$ \\
\hline \multicolumn{5}{|c|}{ Relationship with children ${ }^{\star}$} \\
\hline Mother & 24.5 & 1 & 5.9 & 1 \\
\hline Father & 17.4 & $0.82(0.61,1.09)$ & 6.2 & $1.22(0.77,1.92)$ \\
\hline Grandparents & 15.3 & $0.74(0.38,1.41)$ & 6.2 & $0.91(0.32,2.51)$ \\
\hline Other & 18.8 & $0.85(0.45,1.60)$ & 10.5 & $0.92(0.26,3.21)$ \\
\hline \multicolumn{5}{|l|}{ Hours daily } \\
\hline $0-12$ & 21.7 & 1 & 6.0 & 1 \\
\hline $13-24$ & 26.9 & $1.27(0.94,1.70)$ & 6.6 & $0.73(0.43,1.22)$ \\
\hline
\end{tabular}

Percentages are age standardised by the census population of Catalonia 1991. OR estimates adjusted for age and sex of the child and all the variables in the table. ${ }^{\star}$ Adjusted for all the variables except age and sex of the proxy.
KEY POINTS

- When mothers were the proxy more accidents and morbidity were reported.

- A minimum set of data should be collected from the proxy respondent (age, sex, relationship) to evaluate different patterns of response.

- Characteristics of proxy respondents in children's health surveys need further assessment.

cases, but grandparent and others were the most frequent among families with more than five members and of lower social position

Table 2 shows the model fitted to explain the health characteristics of the child in relation to the characteristics of the proxy. The perception of health status was reported as fair/poor more frequently among children in lower social classes $(\mathrm{OR}=2.04 ; 95 \% \quad \mathrm{CI}=1.12$, 3.70). Health status perception as fair/poor was associated with looking after the child for more than 12 hours daily $(\mathrm{OR}=2.53 ; 95 \% \mathrm{CI}=1.51$, 4.01).

The probability of reporting chronic conditions was greater in children in lower social classes $(\mathrm{OR}=1.49 ; 95 \% \mathrm{CI}=1.15,1.92)$. The proxy respondents over 55 years old $(\mathrm{OR}=$ $0.47 ; 95 \% \mathrm{CI}=0.26,0.82)$, $\operatorname{men}(\mathrm{OR}=0.69$; $95 \% \mathrm{CI}=0.53,0.89)$, fathers $(\mathrm{OR}=0.66$; $95 \% \mathrm{CI}=0.50,0.89)$, and grandparents (OR = $0.49 ; 95 \%$ CI $=0.26,0.89)$, reported a lower rate of chronic conditions.

Chronic restriction of activity was more probable among children in the lowest social class $(\mathrm{OR}=2.35 ; 95 \% \mathrm{CI}=1.17,4.71$ for class III and $\mathrm{OR}=2.44: 95 \% \mathrm{CI}=1.32,4.49$ for classes IVa-IVb-V). No variables related to the proxy respondent were associated with chronic restriction of activities. Table 2 also shows that age of the proxy respondent $(>55$ years) $(\mathrm{OR}=$ $0.41 ; 95 \% \mathrm{CI}=0.20,0.82)$, $\operatorname{men}(\mathrm{OR}=0.70$; $95 \%$ CI $=0.52,0.94)$, fathers $(\mathrm{OR}=0.68$; $95 \% \mathrm{CI}=0.49,0.92)$, and grandparents (OR = $0.40 ; 95 \%$ CI $=0.18,0.85)$ showed a lower probablity to report accidents.

Table 3 shows the characteristics of the children and proxies in the reported use of health services, adjusting simultaneously for all the variables. The health problems significantly associated with a greater probability of physician visits in the last 15 days were the presence of a chronic condition $(\mathrm{OR}=1.99 ; 95 \% \mathrm{CI}=$ $1.54,2.56)$ and restriction of activity in the last 15 days $(\mathrm{OR}=8.53 ; 95 \% \mathrm{CI}=6.33,11.47)$. Hospitalisation in the past year was associated with perceived health status as fair/poor $(\mathrm{OR}=$ $2.13 ; 95 \% \mathrm{CI}=1.12,4.03)$, as well as reporting any chronic condition $(\mathrm{OR}=1.77 ; 95 \% \mathrm{CI}$ $=1.16,2.69)$ or reporting chronic restriction of activity $(\mathrm{OR}=5.51 ; 95 \% \mathrm{CI}=3.21,9.45)$. No characteristics of the proxy were associated with either physician visits or hospitalisation in the last year.

\section{Discussion}

In the health interview surveys involving children, the responses given by the proxy 
respondents are usually considered to be similarly reliable when the informant was the mother or another family member responsible for the child. Although this assumption is not formally investigated in our study, we have found that some characteristics of the proxy respondent are associated to variables of health of the child and thus may probably influence their responses to surveys about childrens' health.

In our study we have found that men, fathers, grandparents, and those over 55 years old reported less morbidity than mothers. Those who care for the child more than 12 hours report more frequently poorer health and accidents.

The association between the proxy respondent being the father or a grandparent and reporting less chronic conditions and accidents could be related to a recall bias, as mothers may well have a greater protective role than other family members. ${ }^{19}{ }^{20}$ Mothers may remember accidents or magnify less important problems when compared with other family members. We do not have data for this hypothesis but clearly further research is needed. The influence of the recall period in determining the prevalence of accidents in US children has been studied in the NHIS using proxy respondents. ${ }^{21}$ This study showed that the incidence of injuries among American children was higher based on a two week recall period than based on a 12 month recall period. The perception of health status as fair/poor was associated with more hours dedicated to caring for the child. In our opinion the result probably indicates a justification of the proxy in relation to their work and responsibility, as suggested by Epstein et al in adults. ${ }^{22}$

The results of our study show that it is necessary to take into account the characteristics of the proxy respondents themselves, like age, sex, and relationship with the child.

There are several limitations of the study. The health status of the proxy respondent is a factor that could influence their perceptions about the health of the child. Unfortunately, the CHIS was not designed specifically for the aim of this investigation and we cannot analyse this hypothesis, but as the studies with proxies for adults suggest, this is an important topic that should be investigated. ${ }^{22}$

We have used "social class" to adjust for socioeconomic characteristics of the child. Nevertheless, it is a characteristic related both with the child and the proxy respondent, who is the mother in $80 \%$ of the cases. This variable was constructed based on the occupation of the head of the family, who is usually the father. There is no consensus on the use of socioeconomic status indicator for children. ${ }^{23}$ Nevertheless, an indicator based on the occupation of the head of the household is one of the traditional indicators and represents an important part of the human, financial, and social "capital" that supports the development of the child. ${ }^{24}$ In our study, similar results were found when using the educational level of the head of the family as an indicator of socioeconomic status (data not shown).
The variable of daily hours dedicated to caring for the child is infrequently used in these types of studies, thus its validity and reliability has not been tested. Behind the care given to the child there are probably other factors such as the worry of the proxy respondent for the welfare of the child. This variable was introduced into the survey based on a conceptual model developed for adults, ${ }^{22}$ in which it is easy to understand the number of hours that each proxy dedicates to the care of the person selected for the survey. Nevertheless, the results show an acceptable internal consistency when crossed with other variables. The proportion of mothers in the 13-24 hour category was higher compared with other members of the family. Moreover, the age of the child was also inversely related to the hours of caring. The employment status of the proxy respondent would be necessary to give further support to the consistency of the hours of dedication.

The use of proxy respondents is indispensable for surveys attempting to determine the health status of a population below a certain age and their use of health services. In addition, the carer is the person who decides to bring the child into contact with health services. According to the results presented, which suggest that proxy respondent characteristics can influence their responses, it would appear desirable that a minimum set of basic data (age, sex, and parental relationship) should be collected from the proxy respondent.

In any health interview survey an attempt should be made to collect the greatest amount of information possible from the person selected, as proposed in the design of NHIS since $1996 .{ }^{25}$ Moreover, it would be useful to have studies on the agreement between proxies and children to try to estimate what is the minimum age after which it is possible to collect information directly from children.

The authors are grateful to the Servei Català de la Salut for providing the original data of the Catalan Health Interview Survey.

Funding: this investigation was partially supported by a grant from the Fondo de Investigación Sanitaria (FIS 97/1113).

Conflicts of interests: none.

1 Krueger DE. Measurement of prevalence of chronic disease by household interviews and clinical evaluations. $A m \mathcal{F}$ Public Health 1957;47:953-60.

2 Tennant A, Badley EM, Sullivan M. Investigating the proxy effect and the saliency principle in household based postal questionnaires. I Epidemiol Community Health 1991;45: 312-16.

3 Mechanic D, Newton M. Some problems in the analysis of morbidity data. F Chron Dis 1965;18:569-80.

4 Rothman ML, Hedrick SC, Bulcroft KA, et al. The validity of proxy-generated scores as measures of patient health staof proxy-generated scores as measu
tus. Med Care 1991;29:115-24.

5 Ontario Ministry of Health. Ontario Health Survey 1990, Ontario Ministry of Health. Ontario Health Survey 1990,
User's guide. Vol 1: Documentation. Toronto: Ontario Ministry of Health, 1991.

6 Sprangers MA, Aaronson NK. The role of health care providers and significant others in evaluating the quality of life of patients with chronic disease. F Clin Epidemiol 1992;45: $743-60$

7 Gilpin EA, Pierce JP, Cavin Sh, et al. Estimated of population smoking prevalence: self-vs proxy reports of smoking status. Am f Public Health 1994;84:1576-9.

8 Poulter NR, Chang CL, Farley TMM, et al. Reliability of data from proxy respondents in an international casecontrol study of cardiovascular disease and oral contracepcontrol study of cardiovascular disease and oral contrace

9 Mosely RR, Wolinsky FD. The use of proxies in health surveys. Substantive and policy implications. Med Care
vest veys. Substantive

10 National Center for Health Statistics. Data evaluation and methods research. Washington DC: Government Printing Office, 1965 (Vital and Health Statistics, Series 2, No 8). 
11 Andersen R, Kasper J, Frankel M. Total survey error. San Francisco: Jossey-Bass, 1979.

12 Herjanic B, Reich W. Development of structure psychiatric interview for children: agreement between child and parent on individual symptoms. $\mathcal{F}$ Abnormal Psychol 1982;10:307.

13 Glaser AW, Davies K, Walker D, et al. Influence of proxy respondents and mode of administration on health status assessment following central nervous system tumours in childhood. Qual Life Res 1997;6:43-53.

14 Adams PF, Hardy AM. Current estimates from the National Health Interview Survey: United States, 1988. Washington DC: Government Printing Office, 1989 (Vital and Health Statistics, Series 10, No 173).

15 Generalitat de Catalunya. Departament de Sanitat i Seguretat Social. Enquesta de Salut de Catalunya 1994. Barcelona: Servei Catala de la Salut, Departament de Sanitat i Seguretat Social, Generalitat de Catalunya, 1996.

16 Magaziner J, Simonsick EM, Kashner TM, et al. Patientproxy response comparability on measures of patient health proxy response comparability on measures of patient health

17 Domingo A, Marcos J. Propuesta de un indicador de la 'clase social' basado en la ocupación. Gac Sanit 1989;10: $320-6$
18 Norussis MJ. SPSS Advanced Statistics 6.1. Chicago: SPSS Inc, 1994.

19 Gryboski KL. Maternal and non-maternal time-allocation to infant care, and care during infant illness in rural Java, Indonesia. Soc Sci Med 1996;43:209-19.

20 Denham SA. Maternal emotional responsiveness and toddlers' social-emotional competence. F Child Psychol Psychiatry 1993;34:715-28.

21 Harel Y, Overpeck MD, Jones DH, et al. The effects of recall on estimating annual nonfatal injury rates for children and adolescents. Am ₹ Public Health 1994;84:599-605.

22 Epstein AM, Hall JA, Tognetti J, et al. Using proxies to evaluate quality of life. Can they provide valid information about patients' health status and satisfaction with medical care? Med Care 1989;27:S91-8.

23 Liberatos P, Link BG, Kelsey JL. The measurement of social class in epidemiology. Epidemiol Rev 1988;10:87-101.

24 Entwisle DR, Astone AM. Some practical guidelines for measuring youth's race/ethnicity and socioeconomic status. measuring youth's race/ethnicitd Dev 1994;65:1421-40.
Child

25 Fowler FJ. The redesign of the National Health Interview Survey. Public Health Rep 1996;111:508-11. 